\section{Dedication to Alan N. Houghton, MD}

\author{
By Daniel G. Coit, MD
}

In 1997, Alan Houghton accepted the position as chairman of the newly assembled NCCN Melanoma Committee. It was from this group of knowledgeable, often opinionated, and occasionally contentious experts in the clinical management of melanoma that the original guidelines were forged.

Beginning with the process of birthing the guidelines and continuing throughout their scheduled reviewing and updating over the past 12 years, Alan's quiet and consistent leadership has encouraged each member's opinion to be heard, emphasized the primacy of data over personal bias, and acknowledged the legitimate controversy of differing approaches to various aspects of melanoma patient care (both in the presence and in the absence of data). Whenever the discussion would digress into questions of managing unusual clinical scenarios, he would keep the group focused on the task at hand, sensibly invoking his "5\% Rule," that guidelines could not possibly substitute for sound clinical judgment in dealing with uncommon events.

In many ways, the NCCN Melanoma Guidelines embody Alan's lifelong commitment to better understanding the complex biology of melanoma, and to applying that knowledge to improve the care of patients afflicted with this disease. On behalf of the NCCN Melanoma Committee, with enormous gratitude and unlimited respect, we would like to dedicate this issue of JNCCN - The Journal of the National Comprehensive Cancer Network to our friend and colleague, Alan N. Houghton, MD.

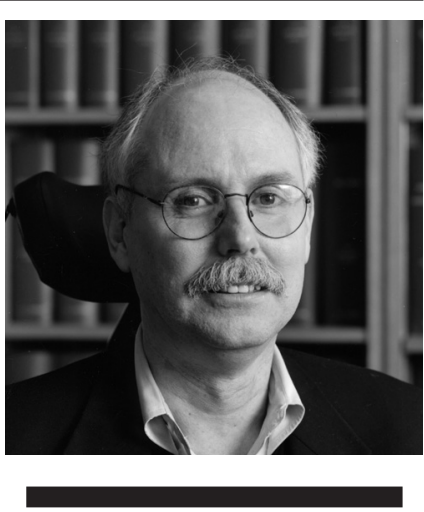

Alan N. Houghton, MD 